\title{
Erratum to: New aspect in seagrass acclimation: leaf mechanical properties vary spatially and seasonally in the temperate species Cymodocea nodosa Ucria (Ascherson)
}

Carmen B. de los Santos • Fernando G. Brun • Juan J. Vergara $\cdot$ José Lucas Pérez-Lloréns

Published online: 10 March 2013

(c) Springer-Verlag Berlin Heidelberg 2013

Erratum to: Mar Biol

DOI 10.1007/s00227-012-2159-3

Unfortunately, in the original version of the article, figure captions 4 and 5 were interchanged. Additionally, in figure 4 caption, two variables were unnecessarily included. The corrected captions along with their Figs. 4 and 5 are given in the following page:

The online version of the original article can be found under doi: 10.1007/s00227-012-2159-3.

C. B. de los Santos $(\bowtie)$ · F. G. Brun · J. J. Vergara •

J. L. Pérez-Lloréns

Department of Biology, University of Cádiz, PO Box 40,

11510 Puerto Real, Cádiz, Spain

e-mail: carmen.barrena@uca.es 
Fig. 4 Variation of mechanical leaf traits of $C$. nodosa per location. Mean values are represented with confident intervals $(95 \%) . F_{\mathrm{TS}}$, specific force-to-tear (tensile strength); $W_{\text {TS }}$, specific work-to-tear (tensile toughness); $L_{\mathrm{T}}$, elongation-to-tear (breaking strain); $E_{\mathrm{T}}$, modulus of elasticity in tension (material stiffness). Locations (from high to low exposure): $\mathrm{CH}$, El Chato (high exposure to waves, intertidal); BC, Bajo de la Cabezuela (medium exposure to waves and currents, subtidal); ST,

Santibáñez (low exposure to waves and currents) with two stations: intertidal (ST-int) and subtidal (ST-sub)
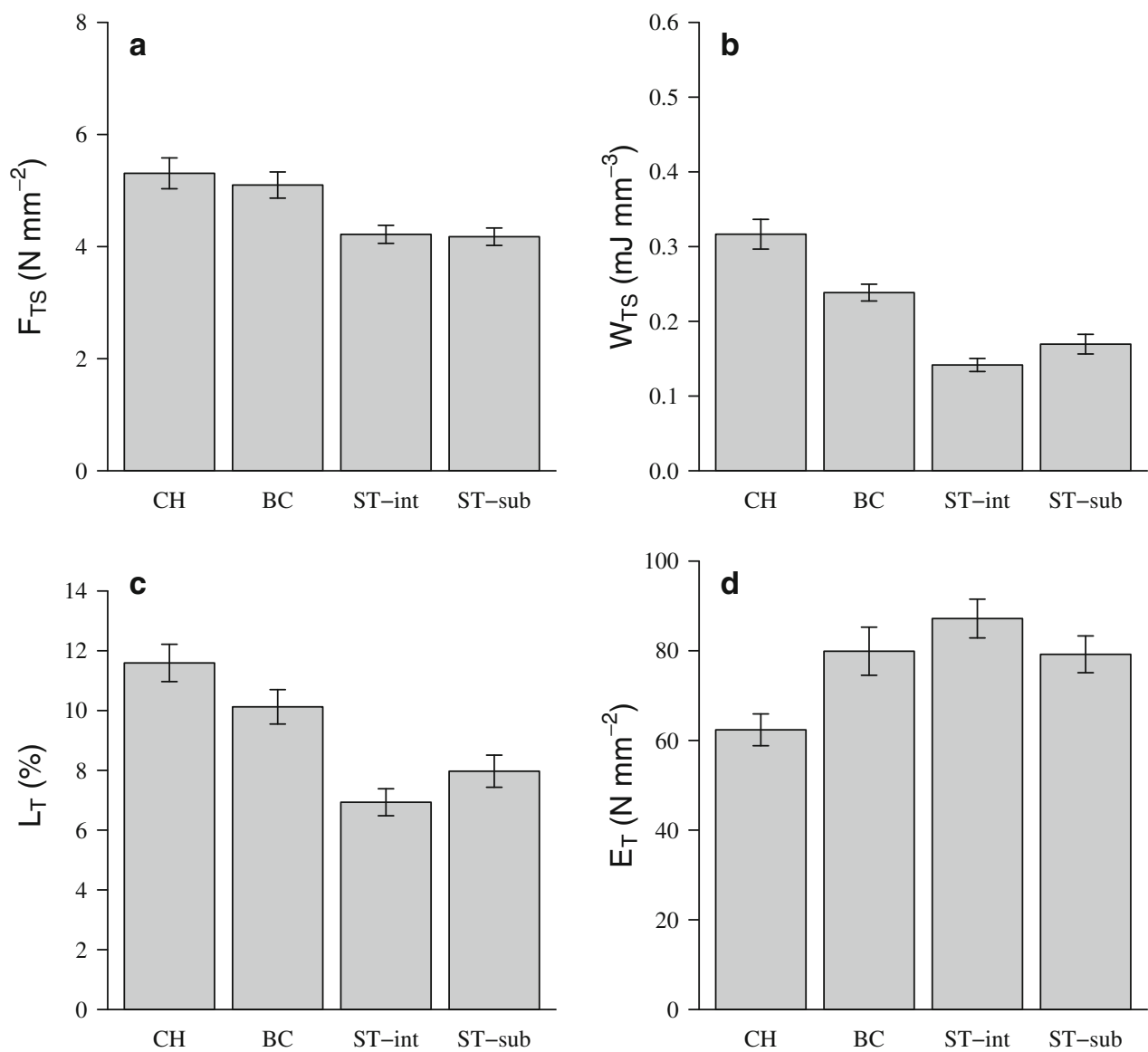

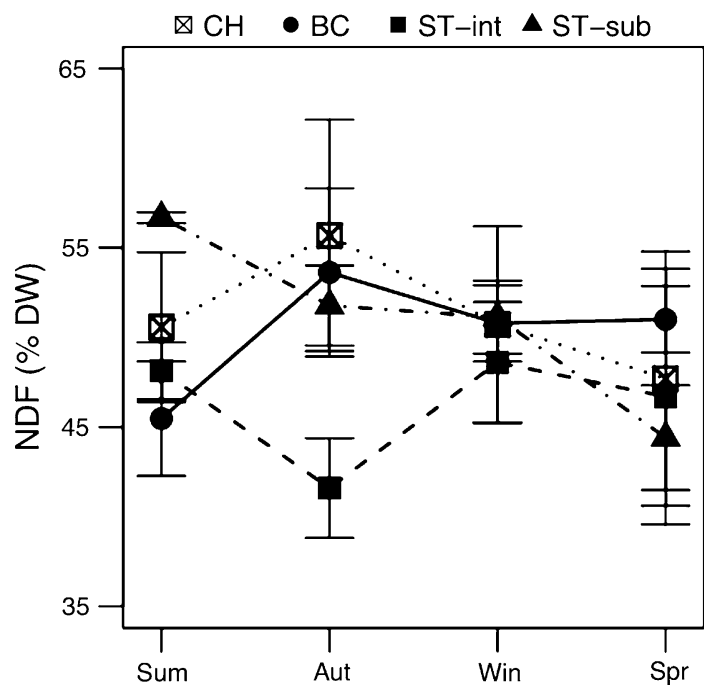

Fig. 5 Seasonal variation of leaf fibre content of $C$. nodosa per location. Mean values are represented with confident intervals (95\%). Locations (from high to low exposure): $\mathrm{CH}, \mathrm{El}$ Chato (high exposure to waves, intertidal); BC, Bajo de la Cabezuela (medium exposure to waves and currents, subtidal); ST, Santibáñez (low exposure to waves and currents) with two stations: intertidal (ST-int) and subtidal (STsub) 